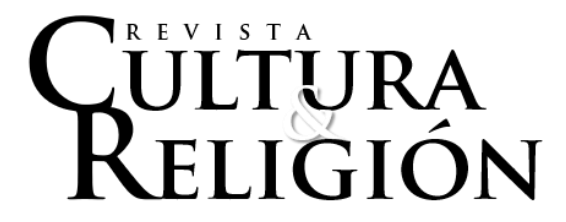

Vol. XIV, N 1 (2020) pp. 142-161

Recibido: 13 de septiembre, 2019

Aceptado: 30 de marzo, 2020

\title{
NARRATIVAS DE IDENTIDAD ISLÁMICA: UNIVERSALISMO, LATINIDADES Y NACIONALISMOS PARA EL CASO DE MÉXICO Y ESTADOS UNIDOS
}

\author{
Narratives of islamic identity: universalism, latinidades and \\ nationalism in the case of Mexico and the United States \\ Arely Medina* \\ Universidad de Guadalajara \\ arely.torres@ cucea.udg.mx
}

\begin{abstract}
Resumen
Este artículo da cuenta de la construcción de narrativas en torno a las identidades islámicas que se construyen como sostén de la práctica islámica en México y Estados Unidos. Para este objetivo, se presentan resultados de proyectos previos en torno a la construcción de la identidad islámica entre mexicanos, latinos musulmanes y migrantes de origen árabe, turco y paquistaní. En estos proyectos prevalece la teoría transnacional en pos de comprender la movilidad religiosa y evidenciar los mecanismos de apropiación del sistema religioso islámico. La mirada transnacional guía en términos metodológicos este trabajo respecto del uso de la etnografía clásica, multilocal y virtual. Finalmente, el argumento que aquí se sostiene alude a que las identidades filiadas al islam, en este contexto, logran posicionarse en tres escalas significativas: la local, la supranacional y la universal, pero con una elaboración construida desde las vivencias como conversos o migrantes, lo que les permite en ocasiones converger discursivamente.
\end{abstract}

Palabras clave: islam, identidad, transnacional, Latinoamérica, conversión.

\begin{abstract}
This article acknowledges the construction of narratives around Islamic identities that have been created as a support for Islamic practices in Mexico and the United States. For this purpose, the results of previous projects on the construction of Islamic identity among Mexicans, Latino Muslims, and migrants of Arab, Turkish, and Pakistani origin are

\footnotetext{
* Profesora-investigadora, Centro Universitario de Ciencias Económico-Administrativas (CUCEA) de la Universidad de Guadalajara (Guadalajara, México). Doctora en Ciencias Sociales, Colegio de Jalisco (Jalisco, México). Miembra del Sistema Nacional de Investigadores del Consejo Nacional de Ciencia y Tecnología (Conacyt) y fundadora de la Red de Investigación sobre el islam en México. ORCID https://orcid.org/00000003-0455-7490
} 
presented. Transnational theory prevails in these projects in order to understand religious mobility and demonstrate the mechanisms of appropriation of the Islamic religious system. In methodological terms, a transnational outlook guides this work with respect to the use of classical, multi-local and virtual ethnography. Finally, the argument advanced here alludes to the fact that identities affiliated with Islam in this context position themselves on three major scales: the local, the supranational and the universal, but with an elaboration constructed from experiences as converts or migrants, which at times allows them to converge discursively.

Keywords: Islam, identity, transnational, Latin America, conversion.

\section{Introducción}

\section{La propuesta: islam y transnacionalismo}

El islam es una religión monoteísta que se desarrolló en la península arábiga a partir del siglo VII, se expandió por el norte de África y llegó hasta países de la actual Asia, convirtiéndose en regiones tradicionalmente islámicas, aunque no exentas de otras prácticas religiosas. Esta región es conocida como el cinturón del Corán (Lubeck y Britts, 2003).

El islam de esta área es diverso. Múltiples prácticas, doctrinas, escuelas jurídicas y exégesis deshomogeneizan el sistema de creencia islámico. No obstante, esta pluralidad tiene en su base religiosa un imaginario social que permite la universalización de la religión y con ello la idea de una comunidad universal, que en su fundamento teológico no distingue entre razas, pueblos o condición social; esta es conocida en árabe como la umma.

El islam como el judaísmo y el cristianismo son religiones monoteístas que se fundaron con la pretensión de universalizar la creencia. Comprender este elemento es fundamental para analizar y dar cuenta de los procesos y alcances del islam en un contexto global, que lo desterritorializa del cinturón del Corán.

La desterritorialización del sistema religioso islámico se debe a diferentes factores sociales. La migración forzada o laboral, los viajes de placer o de tipo proselitista, la industria cultural o los medios de comunicación son canales mediante los cuales se movilizan elementos culturales. Está dinámica puede ser analizada desde la perspectiva del transnacionalismo.

El enfoque transnacional (Levitt y Glick Schiller, 2004; Csordas, 2009; Capone y Mary, 2012) permite salir del lente del nacionalismo metodológico y comprender las dinámicas cambiantes de la sociedad, los Estados y los grupos de individuos en diferentes ámbitos. No privilegia las dinámicas hegemónicas, sino que examina la dialéctica, las tensiones y los ajustes entre las disposiciones del Estado o la hegemonía y los grupos o individuos que posibilitan sus acciones fuera de las intermediaciones del Estado.

En el caso de las religiones, como el islam, esta perspectiva permite hacer un análisis de las heterogeneidades del sistema de creencia. Pone en perspectiva la modernidad y la globalización como sistemas que buscaron la homogeneidad cultural: una dentro de los territorios geopolíticos inventando naciones e identidades homogéneas y particulares, otra saliendo de ellos, y paradójicamente, buscando la homogeneidad en su escala global. La realidad supera estas pretensiones, pero no por ello las elimina, sino que las modela y las ajusta a las realidades locales. De este supuesto, Robertson (2000) ofrece el concepto de 
glocalización. ${ }^{1}$ Observa que los aspectos culturales no se polarizan en la dinámica global y local, sino que incluso en las resistencias locales, las tradiciones, las memorias ancladas a territorios, lo singular que se enfrenta a lo global, lo universal, lo ajeno, están envueltas en dinámicas que son capaces de proyectarse en ese escenario global.

Para entender la dinámica de la glocalización, característica de los procesos transnacionales, se proponen tres fases: deslocalización, translocación o desterritorialización y relocalización de los sistemas culturales o de creencias $^{2}$ (Argyriadis y De la Torre, 2008). La deslocalización de sistemas culturales, religiosos, e incluso de prácticas políticas y económicas puede producirse por la movilidad de agentes hegemónicos: como proyectos de instituciones gubernamentales, proyectos con fines políticos, burocracia, industrias culturales, marketing, negocios transnacionales e incluso las mismas instituciones religiosas con proyectos proselitistas internacionales. Pero también, de aquellos no institucionalizados y que tienen agencia o capacidad para movilizar estos sistemas como los migrantes o viajeros.

En el caso del islam, Lubeck (2004) ubica su movilidad en los inicios de la globalización tecnológica, a través de la política y el negocio internacional entre Estados occidentales y países árabes entre 1973 y 1974 con el boom petrolero. Con ello llegó el intervencionismo, la inestabilidad económica, el fracaso del Estado islámico, el fundamentalismo y el radicalismo islámico, provocando tensiones de carácter político y social. Leído en su conjunto, este período trajo consigo otros modos de practicar el islam, así como reconstrucciones y tensiones de la identidad generadas desde lo nacional, las múltiples etnicidades (Eddin Ibrahim, 1998), lo panárabe y lo religioso. Este fenómeno Lubeck (2004) lo llamó islam global, y Roy (2003), islam mundializado. Ambos autores hacen hincapié en las dinámicas gestadas desde los Estados, acompañadas de la industria y las élites religiosas como juristas o sheijs, universidades, o movimientos islámicos de corte político como la Hermandad Musulmana, y de proselitismo como el Movimiento Jammat ut-tabligh WalDawa (Sociedad para la Propagación y la Oración), entre otros, definiéndose todos en mayor o menor alcance, como autoridades religiosas y políticas.

Es importante señalar que, en este contexto de globalización, lo que figuraba ser particular e incluso patrimonio histórico de la región del cinturón del Corán se globalizó. Lubeck (2004) resalta en ello la creación de una antinomia, la paradójica relación entre globalización y el islam, entre la incorporación de sectores islámicos, sean políticos o financieros en principio, a las dinámicas de globalización, y la creciente tensión entre tradición y modernidad.

Considerando que estas tensiones no solo se dan entre Estados, agentes políticos o petroleros, sino que toca a otros actores afectados por los intervencionismos, las crisis humanitarias y la baja economía se ven orillados a movilizarse: la migración es un ejemplo. Es a través de ella que las tradiciones, ideologías y prácticas colectivas o individuales que permean el islam son puestas en circulación, incursionando en la dinámica transnacional.

\footnotetext{
${ }^{1}$ Glocalización es un término acuñado históricamente en el micromarketing, que se enfoca en la construcción de consumidores de lo global en lo local o de lo local en lo global.

${ }^{2}$ La deslocalización refiere al desanclaje de símbolos, objetos, prácticas, personajes, cosmogonías, que se ponen en circulación en flujos que se dirigen a otros contextos más allá de lo local o nacional. La translocalización apela a lo multilocal, a redes y subredes que funcionan como flujos, circuitos y canales de movilización. Finalmente, en la relocalización, elementos del sistema cultural o religioso logran insertarse en nuevos espacios geográficos, logrando con ello ajustes, cambios, eliminaciones o adhesiones de significados o prácticas.
} 
La migración permite dar cuenta tanto de los acomodos que se generan en el lugar de origen como del contexto de llegada del migrante. Es sobre todo en sociedades laicas donde el migrante musulmán es productor de variadas dinámicas que rozan con la religión para asegurar tanto el mantenimiento de su identidad, como para lograr la integración social. Se ha observado que el islam es un recurso central para lograr la adaptación a estas sociedades -por paradójico que parezca- en sociedades modernas, laicas y seculares, en contraste con lo que se ha definido que es la tradición del islam. Esto puede ser otro resultado de la antinomia que expone Lubeck (2004) y que se puede analizar desde los márgenes de lo sociocultural.

Estudios han revelado que los migrantes musulmanes, generalmente árabes, turcos o paquistaníes, en el lugar de acogida movilizan capitales económicos, culturales, políticos y por supuesto religiosos (Giménez, Montenegro y Setton, 2009; Tarrés Chamorro, 2009). Estos toman forma de asociaciones, ya sean clubs, centros de ayuda, asociaciones connacionales, redes de colaboración y empleabilidad, mezquitas o centros de culto. Tarrés Chamorro (2009) considera que incluso este es un primer paso en el proceso de adaptación. Estos espacios de interacción funcionan como medios estratégicos para integrarse, pero también para palear el imaginario de extranjería y estereotipos. El imaginario de lo árabe o islámico repercute en las formas en cómo el musulmán reconstruye su identidad; sin embargo, es justo mencionar que la identidad colectiva que puede emerger de las agrupaciones no homogeneiza las dinámicas y formas de ser, entender y actuar.

La migración del musulmán tiene diversas causas, que pueden estar desencadenadas por la búsqueda de bienestar social o por constituirse como un proyecto proselitista. Este último, busca unificar a los musulmanes, no solo a los migrantes o de nacimiento, sino incluso a conversos. Tarrés Chamorro (2009) menciona que movimientos como al-tablig permiten ver la operatividad de la transnacionalidad musulmana, es decir:

la red de relaciones que se establecen como la Umma, con la comunidad global de creyentes, independientemente de la nación o país donde se encuentren, y que se fundamenta en la lengua árabe, los viajes a las madrazas para aumentar y profundizar en el conocimiento de las ciencias del Islam y la peregrinación anual a la Meca. (Tarrés Chamorro, 2009, p. 135)

El estudio de la migración de agentes proselitistas es otra arista que permite ver el impacto de nuevas religiones en los contextos de llegada. La presencia de proselitismo es una de las causas de las crecientes conversiones al islam en estos contextos. Observa Pastor de María y Campos (2011) para el caso latinoamericano que el proyecto de unificación de musulmanes y adoctrinamiento contrasta con la diversidad de la práctica al mismo tiempo que la refleja. Sin duda, en esta dinámica no solo la migración ha intervenido, sino la movilización del islam a través de diversos canales que pueden ser hegemónicos, institucionales o creados por la misma agencia de los sujetos, individual y colectiva.

Otras consecuencias de la migración son observadas en la adscripción nacional o adquisición de ciudadanía. Suele haber una redefinición a causa de las tensiones entre la adopción de la nacionalidad receptora y la de origen, así como por los mismos marcos jurídicos. Considérese por ejemplo que en países como Irán, Arabia Saudita, Kuwait, Emiratos Árabes, la nacionalidad solo se obtiene por la línea paterna, de ahí que los hijos o esposos de musulmanas que migran o contraen matrimonio con un migrante no gozarían de su nacionalidad de origen, por lo que se ven en la necesidad de adoptar otra nacionalidad que los cobije. Esto se complica cuando en calidad de migrante solo se cuenta con la residencia, 
no así con la ciudadanía. En otras situaciones, la adopción de una nueva ciudadanía elimina la de origen o se mantiene. Estas posibilidades mencionadas impactan en la reconstrucción de la identidad que se va tejiendo entre religión, nacionalidad y etnicidad. En el escenario de la transnacionalización del islam, las posibilidades son amplias, como variados son los cruces de elementos. Por ejemplo, la participación o por lo menos la simpatía a movimientos islámicos, cualquiera que sea su tipo, puede generar interacción con comunidades internacionales y redes de estudio islámico como universidades, madrazas, o proyectos de proselitismo, así como financiamiento para la construcción o preservación de comunidades y mezquitas, y que ya no solo incluye a la diáspora árabe, sino a otras migraciones de origen islámico, como el turco o el paquistaní, así como a conversos, que son actores activos en la transnacionalización del islam.

En este escenario de amplia movilidad del islam, el presente trabajo ofrece un acercamiento empírico y de análisis de tres amplios casos: el mexicano (Medina, 2014, 2017), el de latinos musulmanes en Estados Unidos (Medina, 2019) y el de migrantes de origen árabe en México, ${ }^{3}$ buscando cruzar información para exponer al lector una imagen reflexiva en torno a las siguientes interrogantes: ¿de qué manera el islam está circulando entre México y Estados Unidos? ¿Cuáles son los canales de difusión del islam que llega a México? Desde la concepción teológica de la umma, ¿cómo es entendida y practicada la universalización del islam frente a la latinidad, la mexicanidad o la arabidad? ¿Qué lugar ocupa la identidad local respecto a lo étnico y la umma? Cuatro preguntas amplias y complejas que demandan ser respondidas a través de la reflexión de siete años de observación en los que se desarrollaron estas tres investigaciones mencionadas. Una mirada transdiciplinaria para abordar el tema de la movilidad religiosa y la migración, como lo propone Odgers (2014), integra métodos de la etnografía clásica, virtual y multilocal para observar la movilidad, circulación, los flujos históricos y las reapropiaciones de los elementos islámicos que posibilitan la identidad, narrativas y prácticas islámicas.

\section{Génesis del islam transnacional en Estados Unidos y México}

El islam es un sistema de creencia que ha sido movilizado por distintas zonas geográficas y culturales, en las que ha demostrado su capacidad de acomodo y flexibilidad para dialogar con las sociedades receptoras. Esto no implicó por supuesto que el sistema de creencia se desprendiera y se relocalizara por completo, sino que devino en diferentes maneras dialécticas que adoptaron variadas formas de vivir y practicar el islam.

En la transnacionalización del islam, una parte del sistema de creencias permanece, sino intacta, como base fundamental y primordial para cualquier denominación islámica, prácticas o interpretación. Se trata de la diversidad de los mundos que propone Nasr (1985), un sistema cultural islámico con distintas zonas o geografías que comparten elementos básicos, pero que están separados por factores locales como lo lingüístico, lo étnico u otro. Estos aspectos básicos son los denominados pilares del islam, ${ }^{3}$ El Corán y en este, incluidas las prohibiciones básicas sobre ingerir productos derivados del cerdo y el alcohol. Lo que

\footnotetext{
${ }^{3}$ Adscrito al proyecto posdoctoral "Reflexiones sobre la gestión de la diversidad: la integración sociocultural en la Zona Metropolitana de Guadalajara de la actual migración del Gran Medio Oriente". Realizado en el Centro de Investigaciones de Estudios Superiores en Antropología Social (CIESAS) durante el 2018-2019.

${ }^{3}$ La profesión de fe, khelime shahada, cinco oraciones al día o salat, ayunar en el mes sagrado de Ramadán, realizar la limosna en este mes, zakat, y la peregrinación o haijj a la Meca.
} 
queda fuera de ello o en la circunferencia de estas normas es lo que puede cambiar, ajustarse o moldearse.

Explicado esto, es posible comprender la práctica del islam en el continente americano. La presencia del islam en esta región data del periodo de la colonización europea. Se sabe que entre las embarcaciones de colonizadores llegaron musulmanes -africanos en calidad de esclavos-, sobre todo a lo que hoy comprende Estados Unidos, México, Colombia y Brasil. Mudéjares o criptomusulmanes también arribaron como acompañantes de navegación (Taboada, 2004) al resto del continente. Reconocer este hecho es fundamental para rescatar la historia, no propiamente del islam como institución, pero sí de musulmanes, y con ello enunciar su temprana presencia para comprender el desarrollo y formas de anclaje de esta religión en el contexto estadounidense y mexicano.

La presencia de musulmanes para el caso estadounidense (Haddad, 2009) y mexicano (Alfaro-Velcamp, 2002) comenzó a finales del siglo XIX y principios del XX con las olas de migración árabe. La institucionalización del islam se dio a mediados del siglo XX para el primer caso y para México hacia finales de la misma centuria. Del siglo XIX hasta mediados del XX, hacia 1965, Hammer y Safi (2013) consideran que comenzó la presencia del islam en Estados Unidos. Bajo la administración de George Washington, Thomas Jefferson y Lyndon B. Johnson, se dio apertura política a la libertad religiosa, por lo que los diferentes credos religiosos, incluido el islam, comenzaron a tomar forma en el contexto multicultural estadounidense.

La particularidad de este contexto de diversidad cultural es que las mismas políticas de gestión de la diversidad de corte asimilacionista o el mismo multiculturalismo que devino en segregación racial, propiciaron que las religiones se instituyeran como organismos de recepción de las diferencias étnicas, raciales y culturales. El islam no fue la excepción, pues la flexibilidad del sistema permitió su adecuación al escenario no solo religioso, sino político y cultural. Su presencia no solo fue el resultado de la migración árabe, sino que su visibilidad se debió también al aumento de la migración de origen indo-paquistaní. Estos últimos, a través de movimientos internacionales proselitistas como el Ahmadiyya y en un contexto racializado, proyectaron su misión proselitista hacia los afroamericanos, de donde surgió por ejemplo la Nación del Islam o el Moorish Science Temple, donde los latinos finalmente se hicieron presentes (Medina, 2019).

Es preciso resaltar que aun con la enmienda de libertad de religión y culto, y en un panorama de aceptación de la diversidad, tanto el islam como otros grupos rompieron con la imagen de una nación para el blanco, anglosajón y protestante, ideal de la nación estadounidense. La presencia del islam y su aceptación han estado atravesadas por períodos de ajustes que se corresponden con los sucesos sociales y políticos de alcance global, y medidas de intervencionismo y proguerra. Por mencionar algo, desde 1965 hasta 2000 hubo una relativa aceptación de los musulmanes no alejada de los estereotipos, pero después del 11 de septiembre de 2001, a raíz de los consecuentes sucesos terroristas, las políticas internacionales incidieron en las acciones locales respecto a la presentación del islam, al reactivarse la alarma internacional para mantener en vigilancia a los musulmanes, incrementando así la xenofobia y la islamofobia.

Al ser una nación vecina de México, Estados Unidos ha estado presente también en sus procesos migratorios. Árabes que tenían como meta el territorio estadounidense, quedaron varados en tierras mexicanas. En este país, las diferentes rutas de llegada desembocaban en los puertos de Tampico, Veracruz y Progreso, Yucatán. Desde ahí algunos migrantes subieron hacia la frontera, sin embargo, las políticas de inmigración y la frontera 
estaban fortalecidas (Massey, Durand, Malone, 2009). Varios de estos migrantes se arraigaron en Tamaulipas, Nuevo León y Coahuila, otros en Yucatán o se movieron a Ciudad de México.

Aunque las temporalidades de esta migración se corresponden con la de Estados Unidos, diferente fue el escenario. Los migrantes que llegaron a México y luego se quedaron, provenían del Imperio Otomano, de la región de Siria, sobre todo en el primer período de migración. Alfaro-Velcamp (2002) contabilizó la llegada de 8.240 árabes entre 1878 y 1951 , de los cuales solo 343 eran musulmanes; dentro de ese período, entre 1922 y 1957, la migración musulmana registró un alza del $56 \%$. La mayoría de esta migración se declaró profesante del catolicismo ortodoxo, maronita o judío-israelita. En comparación con la realidad estadounidense, los musulmanes fueron una cantidad marginal en México. Tras la Segunda Guerra Mundial, la migración de origen árabe se intensificó, evidenciándose una mayor presencia de libaneses, a causa de la guerra civil librada en 1970, y en menor proporción quedó la migración argelina, marroquí, egipcia o siria. En esta migración también se registró un número bajo de musulmanes, por lo que el islam en México para este período quedó relegado a los hogares y no figuró en el escenario religioso, como sí lo fue el judaísmo o el cristianismo maronita.

Mientras en Estados Unidos la migración de origen árabe e indo-paquistaní mantuvo su identidad racial y religiosa, como resultado de las dinámicas de segregación racial, en México, el árabe fue absorbido e invisibilizado, tanto por la dinámica del Estado como por ellos mismos. El desconocimiento o ignorancia, por ejemplo, de los aduaneros provocó que la permanencia de los nombres y apellidos árabes desaparecieran con la castellanización, y lo mismo pasó con su origen nacional: la confusión sobre el Imperio otomano llevó a registrar a migrantes de Siria o Líbano como turcos. La aceptación de estos cambios derivó en una identidad para el espacio público y otra para el privado.

El islam en Estados Unidos logró tener presencia y visibilidad a través de la migración de musulmanes y el proselitismo indo-paquistaní hacia los afroamericanos. En México esto no se logró porque sus practicantes quedaron confinados al hogar. Se tiene registro de solo un caso de organización comunitaria endógena y no tan temprana por parte de libaneses en la Comarca Lagunera en Torreón, que surgió entre 1983 y 1989. En el país vecino, en cambio, el islam afroamericano abrió sus puertas a latinos desde 1920, entre ellos mexicanos e indios nativos. Pero fue a finales del siglo XX y lo que va del XXI cuando surgieron a lo largo y ancho del país organizaciones latinomusulmanas que congregan a musulmanes de origen latino, tanto en espacios físicos como virtuales mediante plataformas de internet (Medina, 2019). Tanto el Moorish Science Temple como la Nación del Islam proyectaron su proselitismo más allá de la comunidad latina en Estados Unidos, llegando a México y otras regiones del caribe (Leonard, 2013; Medina, 2019). También los sufíes neoyorquinos integraron a mexicanos. En 1987, turcos y mexicanos sufíes organizaron la primera tekke en México, vinculada a la orden Halvetti Yerrahí en Turquía. Estas fueron las primeras conexiones entre musulmanes en Estados Unidos y mexicanos.

El islam en Estados Unidos se mantuvo desde un inicio como transnacional, debido a que los migrantes musulmanes mantuvieron vínculos con sus lugares de origen y recrearon comunidad en el lugar de acogida. Además, se crearon vínculos y apoyos con organizaciones islámicas para relocalizar la religión. Por su parte, en México, los árabes mantuvieron también sus vínculos con sus lugares de origen y crearon redes de apoyo, pero no fueron islámicas. Paulatinamente, desde 1986 hasta 1990, la presencia de embajadas árabes influyó en la reunión de musulmanes para el salat al-yamma u oración del viernes (Medina, 2017). 
Poco a poco el islam comenzó a llegar a otros estados de México, como Guadalajara hacia 1993, Chiapas en 1998 a través del Movimiento Mundial Murabitun, Morelia en 2004 con la presencia de migración árabe, en 2014 con la presencia del Movimiento Ahmadiyya en varias ciudades del sur y centro del país, además de la creciente proyección en internet de comunidades o grupos islámicos en diferentes regiones del país.

En los últimos años del siglo XX se generaron conversiones de mexicanos, lo que incrementó el número de practicantes. Desde inicios del siglo XXI, el número de adherentes aumenta como resultado de las conversiones y la migración árabe, turca e indo-paquistaní, lo que cambia el escenario islámico y reconfigura o crea nuevas redes transnacionales. Hay que considerar también el registro de conversiones de mexicanos tanto en Estados Unidos como en México mediadas por internet (Medina, 2014, 2019), la creciente vinculación entre organizaciones latinomusulmanas en Estados Unidos y en México (Medina, 2019), así como con proselitismo internacional (Medina, 2014, 2019).

\section{Del universalismo del islam al particularismo}

La umma es un término árabe que puede traducirse como comunidad. Dentro de la historia del islam, la umma o comunidad islámica se instituyó después de que el profeta Mahoma llegó a La Meca en Medina y proclamó que se había instaurado la comunidad de creyentes, la cual no hacía distinción entre sexos, razas, pueblos, idea expuesta también en el Corán. La institucionalización de la umma no solo fue la creación de un sentimiento de hermandad por la fe espiritual, sino que tuvo aspectos sociales y políticos bajo el sello de los suras medinenses (Zeraoui, 2010).

Desde una perspectiva sociológica, la umma es una comunidad imaginada de corte religioso que, a partir de su supuesto teológico sobre la creación del universo por parte de Alá, recrea el sentimiento de hermandad o compañerismo de forma horizontal y engloba a cualquier musulmán, incluso cuando está fuera de sus límites o fronteras; por lo tanto, es válida y universal en cualquier momento, incluso cuando sus integrantes no se conocen entre sí. En el caso de las religiones basadas en un cosmos sobresalen elementos que permiten su universalización, pero al mismo tiempo sus límites; por ejemplo, la creencia o una lengua sagrada. Anderson (2011) ejemplifica: "Si un maguindanao se encontraba a los beréberes en La Meca, sin que supieran uno el idioma de los otros, incapaces de comunicarse oralmente, entendían sin embargo sus ideogramas porque los textos sagrados que compartían sólo existían en árabe clásico" (p. 31), y nos apunta que, lejos de observar si una comunidad es falsa o verdadera, la comunidad debe ser entendida por cómo es imaginada.

Bajo esta idea de la umma, en el islam la hermandad se sostiene en la profesión de fe, en compartir la creencia de un cosmos específico. En este sentido, son permitidas las conversiones bajo el supuesto de que toda creación de Alá es un muslim. Se habla, entonces, de una reversión, un regreso a las raíces. No es azaroso observar que los discursos o propaganda de proselitismo o dawah usen este argumento, ni que las conversiones entre latinos y mexicanos sostengan que son musulmanes no solo por un rito de paso, sino por un hecho teológico. Desde aquí, los conversos tanto latinos en Estados Unidos como mexicanos en México en calidad de musulmanes o revertidos son capaces de concebirse de manera horizontal como parte de la umma. La manera en cómo lo expresan los musulmanes migrantes o conversos es a partir de su discurso y convivencia basada en normas éticoreligiosas. Por ejemplo, en Irving, California, en una celebración matrimonial entre un converso de origen mexicano y una musulmana egipcia se intercambiaban expresiones en 
torno a las diferencias y tradiciones culturales. Para mediar estas diferencias, se hizo uso de argumentos basados en la igualdad ante Alá y el seguimiento de las normas religiosas como guía de vida. Como conclusión, se acudió al concepto de umma para unificar razas, pueblos, hombres, mujeres y así encontrar armonía (Medina, 2019).

Otra imagen que ilustra el caso es el de una pareja de conversos mexicanos que viajaban hacia Medina. En su trayecto hicieron una parada de un par de días en Inglaterra, donde sin previa familiarización o conocimiento, una familia de musulmanes los acogió bajo la consigna de ayudar a sus hermanos en la fe. ${ }^{4}$

La comprensión de la umma en su sentido universal puede darse también en la performance y la construcción de narrativas. Nahela $\mathrm{M},{ }^{5}$ una conversa mexicana radicada en Estados Unidos, visitó en 2015 a varias comunidades islámicas en México, como las de Chiapas, Ciudad de México y Guadalajara, y organizó una marcha nacional para protestar contra el sionismo y la ocupación palestina, todo ello en nombre del islam. Musulmanes migrantes y conversos- vestidos con túnicas, kuffies, kufiyas, jilabas o velos salieron a las calles con pancartas denunciando su inconformidad ante las vejaciones de sus hermanos en la fe y el islam (Medina, 2019). Este es un dato que nos muestra cómo la umma funciona como elemento de pertenencia religiosa, que logra rebasar fronteras geográficas, políticas, raciales e idiomáticas. Impone ciertos códigos éticos y de conducta entre sus integrantes de tal manera que en algunos momentos la afiliación pase de la imaginación a la efectividad.

Pero este suceso tiene otras lecturas que nos llevan de lo universal a lo particular. Nahela M. ha incursionado como representante de tres grupos proselitistas: Why Islam?, Islam in Spanish y Unidos para el Dawah en México. Estas organizaciones pertenecen a tres espacios con objetivos particulares mas no ajenos. Why Islam? es una iniciativa de una organización islámica nacional en Estados Unidos que tiene como fin abrir espacios de tutoría en inglés, español y chino, como un medio de invitación y recepción de nuevos musulmanes. Islam in Spanish es una organización latinomusulmana, situada en Texas, Estados Unidos, que fomenta el proselitismo, la educación religiosa y los servicios islámicos en español, y eventualmente visita mezquitas en México u otros países de América Latina. Unidos para el Dawah es un proyecto de Nahela para ayudar al crecimiento y establecimiento de comunidades musulmanas en México, con recursos donados de otras comunidades en Estados Unidos. Las tres organizaciones son independientes entre sí, pero se transversalizan en diferentes momentos, y cada una invoca la idea de umma desde el nivel que la sitúa; por ejemplo, la umma universal, la umma o comunidad islámica latina, y la comunidad islámica mexicana, respectivamente.

Estos casos nos llevan a repensar en la definición de umma que se construye en escenarios laicos, seculares, heterogéneos. Se trata de la formación de sentidos a partir de niveles diferenciados por rasgos culturales. Estas formaciones cada vez más evidentes entre conversos de Latinoamérica se muestran disruptivas del imaginario común de lo islámico. Musulmanes y organizaciones en América Latina basados en un argumento teológico e histórico dan continuidad a la idea de comunidad, pero dejan de lado el carácter jurídico y normativo con el que nació el fiqh (derecho) o la sharía (ley) para resaltar solo cuestiones éticas de convivencia, donde además puede surgir la identificación con lo étnico o lo nacional, es decir, con la cultura particular. La concepción de esta umma se empareja con lo

\footnotetext{
${ }^{4}$ En los proyectos mencionados, se realizaron una serie de entrevistas, de las cuales se toman fragmentos o referencias para este trabajo. Entrevista a Isa Rojas, 22 de junio de 2010, Ciudad de México.

${ }^{5}$ Entrevista a Nahela Morales, 6 de agosto de 2014, Guadalajara, Jalisco.
} 
que observa Roy (2003), en relación a que es rechazada por quienes buscan trazar una frontera entre la impiedad y la verdadera religión, entre los que buscan reconstruir el Estado Islámico:

La novedad aportada por el paso al Oeste del islam es la desconexión del islam como religión de una cultura concreta. Esto conduce a sus protagonistas a tener que reformular por su cuenta una religión que no descansa ya sobre una evidencia social. Este paso es ante todo individual, pues las instancias colectivas (padres, presión social, cuerpo de los ulemas, legislación estatal) ya no funcionan, ni para decir lo que es el islam ni para imponer cierto conformismo en el comportamiento y las prácticas. (Roy, 2003, p. 20)

La individualidad de la religión es algo común a toda práctica religiosa o espiritual contemporánea. La fe es capaz de pasar de un horizonte universal a una comunidad particular que vive por el compromiso expreso de sus integrantes. En sociedades laicas, la identidad de las minorías religiosas logra incluso resaltar otras pertenencias. Este tipo de identidades religiosas puede variar según los casos, es así como el musulmán, sea de origen árabe o latino, puede designarse bajo el signo distintivo de la etnicidad que, proyectado hacia los sistemas multiculturalistas, recrea comunidades imaginadas en nombre del islam y la etnia.

En América Latina, la umma existe como imaginario de comunión y es invocada en determinados momentos, por ejemplo, para buscar la aceptación entre la diferencia del resto de los musulmanes. Pero debido a esa heterogeneidad de la umma, esta encuentra sus límites en las adherencias étnicas, nacionales, así como culturales. El islam como religión fundada en una cultura deja de verse estrictamente como reproductora de esta, pasando a vivirse como un sistema de normas, códigos éticos y principios teológicos y espirituales, dando apertura a la creación de comunidades que enuncian o invocan otros imaginarios. Es el caso de los latinos musulmanes en Estados Unidos, país donde la religión ha jugado un papel relevante entre los diferentes grupos raciales y minorías étnicas. En una lectura del sistema de gestión de la diversidad, en que el multiculturalismo logró el reconocimiento de las diferencias étnicas, culturales o idiomáticas, se echó a andar la integración a partir de las diferencias, es decir, a través de la segregación o agrupación racial. Las diferentes instituciones religiosas cumplen un papel primordial para la integración por segregación. Aunque parezca una contradicción, es en los centros de culto donde el señalado como inmigrante puede desarrollar su camino a la adaptación social, precisamente entre manteniendo su identidad u origen y aceptando la americanización (Calvillo y Bailey, 2015; Medina, 2019; Loretzen, 2019).

En el caso del islam practicado entre latinos, se conjugaron varios elementos para la construcción de una comunidad de corte étnico. Por un lado, la invocación a la umma fue resultado del debilitamiento de las identidades nacionales, secuela de las diásporas y migraciones a Occidente. Los musulmanes inmigrantes en Estados Unidos buscaron la unión a partir del llamado religioso. Por otro lado, en este proceso y bajo un esquema de integración por segregación racial (Medina, 2019), el panarabismo cumplió otra función. Aunque su construcción no diluyó las pertenencias nacionales, sí las nubló y las agrupó en características lingüísticas y una historia cultural en común que terminó por invisibilizar las diferencias idiomáticas, historias, regionalismos, tradiciones, y de paso otras prácticas religiosas, quedando el islam como representante de esa historia, lo que trajo consecuencias respecto a la diversidad de creyentes. Es así como musulmanes estadounidenses de origen turco, 
asiático, afroamericano o latinos quedaron fuera no solo de la identificación étnica, sino de la recreación de la umma local.

En este sentido, la umma es problematizada por las diferencias étnicas y nacionales, pero se resuelven las tensiones reconstruyendo el sentido de comunidad islámica en un escenario que dialoga global y localmente. La umma que se arabiza en estos contextos es reformulada por conversos y le impregnan sentido a través de elementos que les son culturalmente familiares. Es el caso del islam entre afroamericanos, asiáticos y más recientemente el de latinos que han conformado organizaciones étnicas musulmanas.

Un último eslabón para comprender la conformación de comunidades islámicas étnicas en Estados Unidos es la lectura del espacio social vivido. La paulatina construcción de organizaciones islámicas o mezquitas que funcionan en determinados momentos para recrear la umma, se perfilaron como raciales, acordes con el pentágono racial. De esta manera surgieron las organizaciones afroamericanas, las paquistaníes y árabes, donde latinos que convivieron en ellas sintieron el peso de la diferencia.

La umma ya no logró mitigar las diferencias. La práctica islámica se perfiló en lenguajes culturales o étnicos. Desde las disposiciones del Estado, los grupos étnicos y raciales no son sino clasificaciones que agrupan a personas que tienen un origen "en común" de acuerdo con la ascendencia, cultura, nacionalidad o lugar de nacimiento. Lo hispano, por ejemplo, nació como producto de las relaciones históricas raciales en Estados Unidos para definir a: "a las personas que trazan su origen o descendencia de México a Puerto Rico, Cuba, Centro y Sur América, y otras culturas españolas" (Whitehouse, 1997, p. 19). Con esta lectura, los musulmanes latinos crearon organizaciones islámicas bajo la denominación de hispanas o latinas. Este último concepto remite a la misma lectura y respuesta del contexto social donde están inmersos: "la palabra hispano parecía reforzar la identidad colonial de España en América Latina y, en ese sentido, parecía dejar de lado la identidad latinoamericana, por ejemplo, la presencia indígena o negra en este continente" (Oboler, 2008, p. 428).

La congregación de latinos musulmanes permite que los conversos practiquen un islam en un idioma cultural. Aunque las procedencias son diversas, paralelizan o unifican aquello que sienten como similar, incluidas la trayectoria y luchas sociales en un escenario donde el latino es estigmatizado. Las percepciones raciales han contribuido a crear fronteras de entendimiento, por lo que es común encontrar narraciones en las que los conversos han experimentado rechazo social por su origen y cultura. Esto también es percibido entre comunidades islámicas afroamericanas o árabes, por considerar que lo "latino" es poco compatible con la práctica islámica. Expresiones de latinos musulmanes dejan ver este rechazo:

[...] uno se siente un poco solo y aislado. Por un lado, yo no hablo árabe [...] Cada mezquita que pasaba tenía letreros escrito [sic] en árabe por fuera [...] Me sentía como un extraño y me preocupaba que los musulmanes nacidos en la religión o incluso otros nuevos musulmanes pensarían que yo era un impostor o 'pasando por una fase'. (LADO, 2003, s.p.)

Este tipo de sucesos dio paso a la organización de grupos o espacios de reunión para latinos musulmanes. En ellos se construyeron narrativas de legitimidad para identificarse como musulmanes entre las diferentes comunidades islámicas y frente a las narrativas hegemónicas de los Estados. Estas narrativas son elaboradas a partir de retazos de la historia 
que sitúan al islam dentro de territorio latinoamericano; se recupera y se reconstruye la memoria colectiva e incluso las trayectorias personales en función de una línea de antecedentes y ascendencias religiosas. Hervieu-Léger (2004), bajo la idea de la memoria, refiere que las religiones o espiritualidades contemporáneas tienen la capacidad de activarse mediante la reconstrucción de historias, linajes y tradiciones.

En una sociedad segmentada racialmente y donde el islam aparece como una neoetnicidad, es decir, asociada a una cultura religiosa, y por sobre todo arabizada, se reformula constantemente entre las identidades étnicas. Por ello los latinos reelaboran su historia y linajes religiosos mirando hacia el pasado y a manera de collages recuperan fragmentos de la historia para narrar una historia no contada. La reelaboración de la memoria colectiva de los latinos se dio a partir de buscar un linaje creyente, pues ya no fue suficiente el reconocimiento como musulmanes a través del rito de conversión. El sustento de los relatos coránicos como la idea teológica de muslim o umma no fueron suficientes para presentarse socialmente como musulmanes. Fue la categoría étnica construida desde el Estado la que reforzó e hizo plausible una historia única, sincrética y legitimada en función del sistema de creencias y practicadas a través de lo que se dice y se hace.

Lo latino en esta memoria aparece vinculado históricamente a la ascendencia mora o árabe y a un linaje creyente, el islam como ascendencia. El trazado de la historia recolecta la presencia de musulmanes en la actual España, su derrota y conversión forzosa al catolicismo; rescata raíces africanas, moras y árabes que viajaron a América Latina en calidad de esclavos, sirvientes o artesanos y que vivieron ocultando su fe. Es en este discurso que los latinos musulmanes rompen con la idea de la umma, recreando otra comunidad imaginada de corte étnico.

Este fenómeno es comprensible si miramos que el islam en movimiento ha sido desculturalizado, y las identidades nacionales, raciales o de otro tipo se sobreponen a la neoetnicidad musulmana. En este caso, el islam como dogma no cambia, lo que se trasmuta es la religiosidad, la manera en cómo el musulmán vive su relación con la religión (Roy, 2003). No hay que perder de vista que, si bien las prácticas religiosas contemporáneas suelen ser más individuales, siguen en busca de cohesión, no social entendida como la comunidad territorial, sino como comunidad imaginada. La umma islámica latina es un ejemplo de ella, es una recreación fundada en un linaje creyente, en una historia compartida, y en un territorio rememorado y vivido de manera transnacional, donde el islam ha sido y es movilizado por diferentes actores.

Los latinos musulmanes, representados por diferentes organizaciones y además utilizando diferentes plataformas de difusión tanto a través de internet como en diferentes espacios físicos, nos acercan a una idea de una sola narrativa de identidad islámica latina. Al hablar en nombre de todos los musulmanes latinos, estas organizaciones recrean una comunidad imaginada, que además no solo se remite a Estados Unidos, sino que al ser viajera, se expande más allá de su límites. Representantes de estas organizaciones, así como sus integrantes movilizan los discursos de identidad islámica latina sea por sitios web, canales virtuales, grupos de conversación o redes sociales, en conferencias locales o festivas, festivales como el "Latino Muslim Day" celebrado en Nueva York, o visitas a otros países. Entre otros, está el caso de "Islam in Spanish", que en su actividad proselitista promociona el discurso de la latinidad islámica a lo largo y ancho de Estados Unidos y fuera del país. Líderes de Islam in Spanish han visitado a algunas comunidades de México e incluso participaron en charlas e hicieron donaciones en el Segundo Congreso de Latinas Musulmanas, que tuvo lugar en la Ciudad de México en 2017. 
La creciente comunicación entre comunidades islámicas de latinos estadounidenses y de mexicanos ha permitido que el islam latino sea transnacionalizado. Conferencias, visitas, eventos, dawah e internet son canales para que este discurso viaje además como parte del sistema de creencias y pueda ser relocalizado. De esta manera, el escenario islámico en México comienza a ser diverso, compuesto por la inmigración de origen árabe, turco y paquistaní, los conversos y comunidades locales que pueden o no estar además sujetas a algún movimiento internacional, como los murabitun, ahmadiyya o los sufíes de Halveti Yerrahí, o bien, con vínculos de proselitismo internacional y de educación islámica como la Universidad de Medina o la Universidad Al-Azhar en Egipto. Las comunidades locales se han caracterizado por denominarse bajo el nombre del territorio donde habitan, usar colores nacionales buscando además sintonía con elementos religiosos y del Medio Oriente, pero recientemente en México se han generado otros grupos que se unen al ideal de una comunidad más amplia, la latina. En ella se busca que el islam adquiera un significado en enclave cultural y como legado histórico, prueba de ello es la traducción del Corán (2013) al español, dirigida al público latinoamericano, a cargo de Isa García, un converso colombiano de renombre entre las comunidades islámicas de habla hispana.

No obstante, la recreación de una comunidad imaginada hecha para musulmanes de origen latinoamericano, las identidades individuales o particulares en nombre de otras adscripciones logran sobresalir. Es el caso de las nacionalidades u orígenes que, aunque enmarcados en lo hispano o latino, son capaces de salir y entrar de la frontera étnica cuando es necesaria su invocación.

\section{El islam desde una narrativa nacionalista}

Los procesos migratorios traen como una de sus consecuencias el debilitamiento de las identidades nacionales frente a la adopción de las nacionalidades receptoras, como se ha observado en la migración árabe en Europa (Roy, 2003). Este debilitamiento no es su anulación, porque las identidades aún cuentan con el componente de rememorar el origen nacional y lo que ello trae consigo, que puede ser la cultura, tradiciones, la religión o el idioma, aunque puestos en un nuevo contexto se resignifiquen.

En esta dinámica es comprensible observar que, frente a la creación de una comunidad islámica con fronteras étnicas como las latinas, las experiencias o autodefiniciones de los conversos reclamen un lugar particular. En un estudio de caso a mexicanos musulmanes de La Asociación Latino Musulmana de América (LALMA) -organización que reúne a musulmanes de origen latino en el sur de California, con sede en Los Angeles (Medina, 2019)-, se observaron los matices utilizados para la construcción de la latinidad islámica y la percepción individual sobre ser latino o mexicano. El grupo entrevistado estuvo compuesto por tres hombres y ocho mujeres, de los cuales diez de ellos contaban con la ciudadanía estadounidense y solo uno sin ella.

Cada musulmán mexicano relata su trayecto al islam desde las dinámicas de la globalización del islam, pero es desde sus propias experiencias de migración que describen su identidad religiosa. La identidad latina si bien no es negada, es activada cuando se trata de recrear una comunidad religiosa con matriz cultural valorada en el contexto estadounidense. Lo latino funciona como identificación y diferencia en el pentágono racial y en el sistema de integración por segregación, como vía de legitimación de una práctica religiosa en clave cultural, y como representación de un grupo que históricamente representa lucha social y presencia en una sociedad que, como señala Oboler (2008): 
ser latino implica que no importa el lugar de nacimiento ni la nacionalidad de los padres, ni la nacionalidad de los niños o jóvenes nacidos en Estados Unidos: lo único que importa es la percepción de la sociedad estadounidense de que ellos, como todo latino, no son de Estados Unidos y, por lo tanto, no pertenecen a ese país. (p. 433)

La identidad nacional relatada aquí, encuentra su particularización en las trayectorias de luchas sociales bajo el estandarte mexicano, en las percepciones raciales respecto a los mexicanos, en elementos culturales que son patrimonio de la nación o han sido valorizados como propios de lo auténtico mexicano y que son diferentes a otros nacionalismos. Está anclada en el origen o las raíces que de manera metafórica marcan destino; en ese sentido, ser mexicano en Estados Unidos es identificarse como tal.

Diferentes experiencias de ser mexicano se enmarcan en rememorar elementos o sucesos del pasado. Uno de ellos es recordar el territorio geográfico de las dos Californias, que quedaron divididas geopolíticamente en una California mexicana y otra estadounidense. Entre los relatos de estos conversos es común la referencia a la imagen de que los mexicanos no migraron, la frontera los dividió, situándolos en condiciones inferiores a las que ellos social y políticamente tenían. Otra remembranza es la reconstrucción narrativa de las rutas de cruce de México a Estados Unidos, todas ancladas a las políticas de migración, así como las dificultades de asentamiento y comprensión de una nueva posición social y cultural.

En este último punto, el mexicano que migra al país vecino se encuentra por primera vez en un contexto donde se le cuestiona su origen, identidad y pertenencia a la nación. Por primera vez, el mexicano criollo se reconoce como un sujeto no blanqueado, y junto al migrante de origen indígena es catalogado como latino o hispano. Su autorreconocimiento como hispano se traduce en estrategia de aceptación para lograr la integración, pero al mismo tiempo lo pone entre paréntesis para resaltar la identidad nacional. Las narrativas de estos conversos plantean el alejamiento de lo hispano o latino como muestra de una resistencia hacia la asimilación, tal como lo expone César:

Lo latino lo considero así: una persona nacida o criada aquí (Estados Unidos). Yo nací aquí, pero no me críe aquí, yo me críe en México. Entonces, no me parecería justo, de acuerdo con los parámetros de lo que se considera ahora latino. Yo digo ahora porque hace 20 años no existía este término. Y entonces para evitarlo, yo soy mexicano-estadounidense. (Entrevista personal, 2014)

Cabe resaltar que la mexicanidad como identificación no los aleja de las narrativas que construyen la memoria islámica latina. Hay un reconocimiento al palimpsesto árabe o islámico, por lo que lo mexicano y el linaje islámico no se vuelven contradictorios:

Me puse a ver, a informarme del apellido de mi padre, Moreno [...] viene de España, pero el Moreno viene de los [moros], estaban en España y eran morenos, y entonces se agarraron de ese apellido. Entonces yo pienso que sí [tiene linaje]. (Entrevista personal a Moreno, 2015)

No obstante, el palimpsesto no siempre está anclado al linaje de sangre, sino a la cultura mudéjar, que es entendida por estos conversos como lo árabe. En este sentido, no todas las narrativas sostienen la existencia de un linaje, como es el caso de conversos con origen indígena. 
La nacionalidad mexicana es sostenida como un elemento cultural capaz de entrar y participar de lo latino, pero también de distanciarse. Lo mexicano además es constantemente reforzado a partir de la interacción entre connacionales, los retornos circulares al lugar de origen, así como de bienes culturales. Entre estos conversos, además, se integra también las visitas ocasionales a comunidades islámicas de la región de origen o el proselitismo de las organizaciones latinomusulmanas, teniendo a los mexicanos como conductores de estas. El musulmán mexicano como transmisor del discurso religioso muestra un islam desarabizado y compatible con la cultura mexicana, que se simboliza por ejemplo a partir de colores nacionales, sombreros charros, botas o tejanas, festejos con comidas halal (permitidas) a la mexicana. En este contexto de relocalización, el islam aparece como un sistema flexible, capaz de integrar lo mexicano y una pluralidad de raíces culturales, incluso las indígenas. En estas adscripciones de identidad, se es latino con la comunidad y como parte de la lucha social; se es mexicano como rescate de raíces, pertenencia histórica al territorio y como alteridad frente a clasificaciones normativas que homogenizan las diferencias. La identidad juega un papel flexible según la lectura que el actor hace de su entorno. Setton (2017) apunta, por ejemplo, respecto a la identidad étnica que esta "sucede cuando se activan determinados esquemas de comprensión de la realidad y definición de la situación. En este sentido, el actor se etniciza en la medida en que define situaciones en función de estos esquemas" (2017, p. 69).

Lo latino y lo mexicano, expresado así, solo es comprensible en su seno de formación: un contexto de resistencia, de gestión de la diversidad y de estrategias de legitimación. Este fenómeno puede ahora leerse a la par de los acomodos que se están observando para el caso mexicano. El converso en México reelabora su identidad en función de la umma internacional, bajo los principios básicos de la fe y su adscripción a comunidades locales. La intervención de agencias de proselitismo internacional ha tenido la función de educar y formar a líderes, más no existen otras comunidades islámicas que cuestionen la legitimidad de la práctica o pertenencia, sino que es más que suficiente el argumento teológico y el sentido de reversión. No obstante, la reciente marcada presencia de musulmanes migrantes, sean de origen árabe, turco o paquistaní, comienza a reformular los espacios de convivencia y sentido de la práctica.

Para el caso de Guadalajara, la migración contemporánea de musulmanes puso en debate la organización de la comunidad islámica que albergaba tanto a conversos como a migrantes. Entre 2009 y 2013, la comunidad llamada Islam en Guadalajara reunía a todos los musulmanes, pero pronto cambió su rumbo. Islam en Guadalajara se perfiló como la comunidad para migrantes de origen árabe y paquistaní, mientras los turcos solo esporádicamente visitan la musallah. Los conversos, por su parte, se organizaron para crear la mezquita Isa Ibn Maryam, donde practican islam en español y bajo su propio entendimiento. La existencia de dos mezquitas no implica el cierre para unos u otros. Según explica Haidar (Entrevista, 2018), los conversos no tienen la misma intención que los migrantes: el converso hace proselitismo porque busca atraer a nuevos musulmanes, mientras el migrante no está interesado en hacer dawah, sino en trabajar y encontrar bienestar social. Esta migración no encuentra su causa en el proselitismo religioso, sino en lo laboral.

Haidar es uno de los migrantes que fueron entrevistados durante esta investigación. El perfil de esta migración corresponde a hombres de entre 27 y 38 años de edad, procedentes de Marruecos, Egipto, Siria y Turquía, que arribaron a México entre el año 2008 y 2016. Se trata de una generación que vive la precariedad social, económica y la falta de empleo, por 
lo que la migración está centrada en lo laboral. Las narrativas de identidad, en este sentido, no se enfocan en la matriz religiosa, sino en la arabidad o la identidad turca, que como componente cultural absorbe lo islámico.

La etnicidad para el árabe y la identidad nacional para el turco o paquistaní, en este contexto de migración tiene el poder de congregar. La arabidad tiene la capacidad de minimizar las identidades nacionales -aunque no olvidarlas- y exaltar los rasgos comunes, como el idioma, la gastronomía y la religión. El turco y el paquistaní, en cambio, no tienen esa opción: es el llamado a la nación lo que les permite marcar diferencia. Pero es importante señalar que el ser migrante y musulmán adquiere sentido en un espacio común, ya que estos grupos usan el recinto sagrado para conmemorar sus tradiciones, hablar en su idioma y recrear el hogar que dejaron atrás. El converso en cambio usa la musallah o mezquita como un espacio donde refuerza su identidad religiosa, comparte sus inquietudes y sus procesos de conocimiento y educación religiosa.

Con esto se pone en evidencia que migrantes y conversos tienen objetivos diferentes de la práctica religiosa y con ello respecto del lugar que funciona como recinto. Para los primeros es un recinto de adoración, pero también de recreación cultural. Para los segundos es lugar no solo de adoración, sino de aprendizaje y reformulación de la identidad religiosa. No obstante, ambos son capaces de invocar la umma cuando es menester, por ejemplo, en las celebraciones anuales como el Ramadán o la fiesta de sacrificio, cuando el significado teológico de la umma los reúne. Son identidades discursivas generadas por procesos de significación individual y colectiva que al mismo tiempo que se relacionan en su contexto local, lo configuran y se despliegan a otros entornos.

\section{Conclusiones}

En los casos aquí descritos, la posibilidad de ser musulmán no solo es viable a partir del ritual de conversión. La shajada o testimonio de fe es reforzada por las narrativas de rescate de la memoria, linaje creyente y sentido teológico. En un contexto de migración y donde los sistemas culturales, religiosos, ideológicos se transnacionalizan, el islam es descontextualizado del cinturón coránico, del islam como cultura o como tradición inscrita en la sharía. En cambio, el islam relocalizado es transformado en una práctica religiosa capaz de latinizarse, mexicanizarse o reforzarse vía la arabidad o el ingrediente nacional acorde con el migrante, y esto se da según las rutas de identidad, lo que permite por un lado romper la idea estereotipada del árabe como musulmán para el caso del converso, pero por otro erigir la bandera del islam como un componente intrínseco a su naturaleza cultural para el caso del migrante.

La imagen del árabe en el contexto estadounidense se sustituye por la reconstrucción del musulmán latino que, sin embargo, es capaz de mantenerse abierta, pues al mismo tiempo que se limita a una práctica entre latinos, se abre a la comunidad islámica a partir de afinidades y valores religiosos, y opera como defensa de los musulmanes en el mundo, es decir, logra entrar en la umma. Es perceptible que las identidades que se están formulando con los latinos musulmanes son identidades en resistencia, de reclamo por salvaguardar la latinidad, presentar una historia contrahegemónica en una panorámica no solo local, sino transnacional, lo que se traduce en una reconstrucción de la memoria islámica en búsqueda de legitimidad religiosa. La conversión al islam se transforma en un proyecto colectivo para demostrar que a partir de la latinidad se puede delimitar una nueva frontera cultural. Ser 
latino y musulmán es el proceso de negociaciones y de desafíos a las categorías tradicionales de lo latino y del islam.

La creciente comunicación entre latinos musulmanes en Estados Unidos con musulmanes de otras latitudes en América Latina está abriendo un canal de propagación del mensaje del islam latino, por lo que vale la pena en futuras investigaciones analizar las formas y éxitos de la transnacionalización de este mensaje.

En México, aunque es evidente la comunicación continua entre mexicanos o latinos musulmanes de Estados Unidos, este mensaje es apenas visible. Para el caso mexicano, la latinidad como una construcción étnica islámica aún no cobra atención. Pero si logra reunir a musulmanes de América Latina bajo convenciones o reuniones que se pintan de diversos colores nacionales; es decir, con elementos que permitan distinguir al converso musulmán de la umma global, quizás estas sean las semillas de lo que podría devenir en discursos de la elaboración de una comunidad imaginada islámica y latinoamericana.

De manera inversa, mas no distante de sentido, se encuentra el migrante en México. Este recobra el sentido de umma desde su arabidad o pertenencia nacional, como es el caso de paquistaníes o turcos. Es la religión la que se ancla a la identidad étnica o nacional, es el componente que se teje con la cultura, y su práctica el momento de conectarse con sus raíces. No obstante, ambos, conversos e inmigrantes, son capaces de convocar su pertenencia a la comunidad universal de creyentes.

Los casos expuestos aquí muestran los niveles en los que se puede imaginar la comunidad y la pertenencia. Entender los contextos en que se da la práctica islámica nos adentra en la heterogeneidad de la práctica y en las posibilidades que tiene el islam como un sistema de creencias capaz de ser reformulado y de mantener su pervivencia. Las prácticas de los actores dejan entrever la gestión y las tensiones de la diversidad étnica y nacional al interior de la idea de una comunidad islámica.

Lo que finalmente nos queda son varias interrogantes abiertas, que sin duda trabajos más amplios podrían dar cuenta de las rutas, circuitos, redes del islam en América Latina, sus alcances, éxitos o fracasos y negociaciones en contextos glocales. Desde estas interrogantes será imprescindible discutir, por ejemplo, los procesos de secularización y el papel del islam, así como su actuar en diferentes contextos, el roce de los musulmanes con otras áreas sociales, los imaginarios sociales recreados por la religión, entre otros desafíos que la presencia del islam contemporáneo está dejando en evidencia.

\section{Referencias bibliográficas}

Alfaro-Velcamp, T. (2002). Mexican muslim in the twentieth century: challenging stereoptypes and negotiating space. En Y. Haddad (ed.), Muslim in the West. From Sojourners to Citizens (pp. 278-293). Nueva York: Oxford University Press.

Anderson, B. (2011). Comunidades imaginadas. Reflexiones sobre el origen y la difusión del nacionalismo. México: FCE.

Argyriadis, K. y De la Torre, R. (2008). Introducción. En K. Argyriadis, R. de la Torre, C. Zúñiga y A. Aguilar Ros (coords.), Raíces en movimiento. Prácticas religiosas tradicionales en contextos translocales (pp.11-42). Zapopan: El Colegio de Jalisco, Centre dÉtudes Mexicaines et Centraméricaines, Institu de Recherche pour le Développement, CIESAS-Occidente, ITESO. 
Calvillo, J. y Bailey, S. R. (2015). Latino religious affilation and ethnic identity. Journal for the Scientific Study of Religion, 54(1), 57-78.

Capone, S. y Mary, A. (2012). Las translógicas de una globalización religiosa a la inversa. En K. Argyriadis, S. Capone, R. de la Torre y A. Mary (coords.), En sentido contrario. Transnacionalización de religiones africanas y latinoamericanas (pp. 27-46). México: CIESAS, Academia/L'Harmmattan, Institut de Recherche Pour le Développement, Publicaciones de la Casa Chata.

Castells, M. (2009). La era de la información. Economía, sociedad y cultura. El poder de la identidad. México: Siglo XXI editores.

Csordas, T. (ed.) (2009). Transnational Transcendence: Essay on Religion and Globalization. Berkeley: University of California Press.

Díaz Cruz, R. (1993). Experiencias de la identidad. Revista Internacional de Filosofía Política, $\mathrm{N}^{\circ}$ 2, 63-74. [Consultado el 19 de julio de 2016]. Recuperado de: http://espacio.uned.es/fez/eserv/bibliuned:filopoli-1993-2-7AA3DF76-3C0B-D4CD-B983711F75FF631E/experiencias_identidad.pdf

Eddin Ibrahim, S. (1998). Los conflictos étnicos y la construcción del Estado en el mundo árabe. Revista Internacional de Ciencias Sociales, $N^{\circ}$ 156, 1-24. [Consultado el 27 de marzo de 2019]. Recuperado de: https://centroderecursos.cultura.pe/sites/default/files/rb/pdf/Los-conflictos-etnicosy-la-construccion-del-Estado-en-el-mundo-arabe.pdf

El Corán (2013). Traducción de Lic. M. Isa García. Bogotá: sin editorial.

Giménez, V. B., Montenegro, S. y Setton, D. (2009). 'Árabes en la selva'. Migración, religión e identidad en el imaginario de católicos y pentecostales. En O. Odgers Ortiz y J. C. Ruiz Guadalajara (coords.), Migración y creencias. Pensar las religiones en tiempo de movilidad (pp. 101-130). México: El Colegio de la Frontera Norte, El Colegio de San Luis, Miguel Ángel Porrúa.

Haddad, Y. (2009). The shaping of arab and muslim identity in the United States. En R. Alba, A. J. Raboteau y J. DeWind, Immigration and Religion in America. Comparative and Historical perspectives (pp. 246-276). Nueva York: New York University Press.

Hammer, J. y Safi, O. (2013). Introduction: American Islam, Muslim Americans, and the American Experiment. The Cambridge Companion to American Islam (pp. 1-14). Cambridge, UK: Cambridge University Press.

Hervieu-Léger, D. (2004). El peregrino y el convertido. La religión en movimiento. México: Ediciones del helénico.

Hervieu-Léger, D. (2005). La religión, hilo de memoria. Barcelona: Herder.

LADO. (2003). Juan Galván. Pensamientos entre los musulmanes latinos. La voz del musulmán latino. [Consultado el 5 de mayo de 2014]. Recuperado de: http://latinodawah.org/newsletter/jan-mar2k3.html\#3

Levitt, P. y Glick Schiller, N. (2004). Perspectivas internacionales sobre migración: conceptuar la simultaneidad. Revista Migración y Desarrollo, $\mathrm{N}^{\circ}$ 3, 60-91.

Leonard, K. (2013). Organizing communities: institutions, networks, groups. En J. Hammer y O. Safi (eds.), The Cambridge Companion to American Islam (pp. 170-188). Nueva York: Cambrigde University Press.

Loretzen, L. A. (2019). Religión e inmigración. Enfoques teóricos. En A. Carpio Pérez e Yves Bernardo (coords), Migración y religión (pp. 27-51). México: Universidad Panamericana-CEHILA. 
Lubeck, P. (2004). El renacimiento islámico. Antinomias de los movimientos islámicos en el contexto de la globalización. Revista Estudios de Asia y África, 39(123), 41-73.

Lubeck, P. y Britts. B. (2003). La sociedad civil musulmana en los espacios públicos urbanos: globalización, cambios discursivos y movimientos sociales. Revista Estudios de Asia y África, 38(122), 477-519.

Massey, D. S., Durand, J. y Malone, N. J. (2009). Ensamblaje de la maquinaria: una historia de la migración México-Estados Unidos. Detrás de la trama. Políticas migratorias entre México y Estados Unidos (pp. 31-60). México: Miguel Ángel Porrúa.

Medina, A. (2014). Islam en Guadalajara. Identidad y relocalización. Zapopan: El Colegio de Jalisco.

Medina, A. (2017). El islam en México. Revisión histórica de su inserción al escenario religioso mexicano. Revista de Historia Vuelo libre. Minorías religiosas, enero-junio, $\mathrm{N}^{\circ}$ 5, 5-17. [Consultado el 16 de octubre 2018]. Recuperado de: http://www.vuelolibre.revistadehistoria.cucsh.udg.mx/sites/default/files/2_el_islam en_mexico._revision_historica_de_su_insercion_al_escenario_religioso_mexicano. pdf

Medina, A. (2019) Islam latino. Identidades étnico religiosas. Un estudio de caso sobre los mexicanos musulmanes en Estados Unidos. Zapopan: El Colegio de Jalisco, El Colegio de la Frontera Norte, Rifrem.

Nars, S. H. (1985). Vida y pensamiento en el islam. Barcelona: Helder.

Oboler, S. (2008). La identidad latina de ayer y hoy. En E. Levine (ed), La migración y los latinos en Estados Unidos. Visiones y conexiones (pp. 427-445). México: UNAM, CISAN. [Consultado el 14 de octubre de 2015]. Recuperado de: http://www.cisan.unam.mx/virtuales/pdfs/migracionLatinos/21.Suzanne\%20Oboler $\% 202$ da..pdf

Odgers, O. (2014). Migración y cambio religioso en México: perspectivas de análisis y agenda de investigación. Revista Cultura y Religión, 8(1), 151-167.

Pastor de María y Campos, C. (2011). Ser musulmán nuevo en México: la economía política de la fe. ISTOR. Revista de Historia Internacional. El islam en América Latina, 12(45), 54-75.

Robertson, R. (2000). Glocalización: tiempo-espacio y homogeneidad heterogeneidad. Zona Abierta, $\mathrm{N}^{\circ}$ 92-93, 1-29.

Roy, O. (2003). El islam mundializado. Barcelona: Ediciones Bellaterra.

Setton, D. (2017). Aportes al estudio de la etnicidad a través de una investigación sobre judíos no afiliados a organizaciones judías. Revista Cultura y Religión, 11(2), 51-69.

Taboada, H. (2004). La sombra del islam en la conquista de América. México: UNAM-FCE.

Tarrés Chamorro, S. (2009). Movimientos de piedad islámicos en la inmigación: La yama’a at tablig al-da'wa en Andalucia. En O. Odgers Ortiz y J. C. Ruiz Guadalajara (coords.), Migración y creencias. Pensar las religiones en tiempo de movilidad (pp. 131-160). México: El Colegio de la Frontera Norte, El Colegio de San Luis, Miguel Ángel Porrúa.

Whitehouse (1997). Revisions to the Standards for the Classification of Federal Data on Race and Ethnicity. Washington: Executive Office of the President. [Consultado el 13 de junio de 2020]. Recuperado de: https://nces.ed.gov/programs/handbook/data/pdf/Appendix_A.pdf 
Zeraoui, Z. (2010). Islam: religión y Estado. En Z. Zeraoui (coord.), El islam en América Latina (pp. 11-32). México: Limusa, Instituto Tecnológico y de Estudios Superiores de Monterrey.

\section{Cómo citar este artículo}

Medina, A. (2020). Narrativas de identidad islámica: universalismo, latinidades y nacionalismos para el caso de México y Estados Unidos. Revista Cultura \& Religión,14(1), 142-161. 